\title{
Frequency of symptoms associated with gallstone disease: a hospital- based cross sectional study
}

\author{
Leila Kanafi Vahed (1), Leila Khedmat (2) \\ (1) Department of Community Medicine, Gilan University of Medical Sciences, Gilan, Iran; (2) \\ Department of Community Medicine, Tehran University of Medical Sciences, Tehran, Iran
}

This article is distributed under the terms of the Creative Commons Attribution Noncommercial License (CC BY-NC 4.0) which permits any noncommercial use, distribution, and reproduction in any medium, provided the original author(s) and source are credited.

\begin{abstract}
This study investigated the likely outcomes of gallstone disease and frequency of symptoms associated with this. This cross sectional study was performed at the Aliebn Abitaleb hospital in Rafsanjan over a period of twelve months from 2000 to 2001. A total sample of 70 individuals were included in the study, interviewing them using of a questionnaire covering data in terms of demographic features and medical history.The majority of patients belonged to the age group of 41 to 60 years (44.3\% of all patients), while the lowest frequency was in the age group of 20 years or less. Frequency of females was higher than males. The frequency of female patients increased with the number of child birth, the highest being in women who had more than 5 child births. The most common complaint of pain was revealed as upper right abdominal quadrant (RUQ), which accounted for $95.7 \%$ of cases. Vomiting was observed in $52.9 \%$ of patients. In addition, the frequency of patients with chronic pain initiation was more than those with acute pain initiation. Among women, $17.5 \%$ had oral contraceptive pill constipation. It is worth noting that ultrasonography was the best diagnostic tool for evaluating patients. It is noteworthy that the most common symptom was right upper quadrant tenderness. Our data indicate that diabetes was the most common illness associated with gallstone disease and that $8.6 \%$ of patients had a family history of gallstone disease.
\end{abstract}

Key Words: gallstone disease, child birth, ultrasonography, frequency

Gallstone disease is a common cause for hospital admission and surgical emergency all over the world. ${ }^{1,2}$ Despite its prevalence in the general population and significant burden for the health care system, there are only a few determinants of gallstone formation. ${ }^{2}$ Different factors can influence gallstone disease including age, previous pregnancies gender, genetics, parity, oral contraceptives, diet, sedentary lifestyle, obesity and body fat, physical activity, type 2 diabetes mellitus, drug constipation, etc. ${ }^{3}$ The prevalence of disease has geographic variations. ${ }^{4-6}$ The incidence of biliary stones is between $10 \%$ and $15 \%$ of the adult population, where most people usually have an asymptomatic gallstone disease. ${ }^{7}$ Gallstone disease occurrence increases with age, but one quarter of women over the age of 60 present it, ${ }^{3,8,9}$ Iran included. ${ }^{10}$ Gallstones is associated with genetic and environmental factors. In people with a family history it occurs three times more in first-degree relatives than other individuals. ${ }^{7}$ Pain caused by gallstones is associated with a series of symptoms, in particular in the upper right abdominal quadrant. Abdominal pain appears in the general population, but is not necessarily related to gallstones. $^{12,13}$ Gallstone disease is associated with the presentation of biliary colic and acute cholecystitis. There are many complications in gallstones such as gallbladder empyema and gallbladder mucocell, jaundice due to biliary stones or Mirizzi's syndrome, as well as acute pancreatitis. ${ }^{13}$ People with gallstone often experience other disorders that can lead to inaccurate diagnosis and complicate decision-making in relation to cystectomy. ${ }^{14,15}$ The current study aimed to evaluate the occurrence of gallstone disease in patients who were admitted to the hospital of Aliebn Abitaleb in Rafsanjan.

\section{Materials and Methods}

\section{Ethical considerations}

This descriptive-cross sectional study was performed on 70 patients admitted to the hospital of Aliebn Abitaleb in Rafsanjan from 2000 to 2001. After explanations were 


\section{Gallstone disease}

Eur J Transl Myol 28 (2): 198-202, 2018

given to patients the necessary examinations were performed with the permission of the patients.

\section{Variables}

The variables of this study were selected based on patient records, biographies, diagnostic methods and replies in the questionnaires. These variables were: 1. Form of hospitalization; 2. Complaints and reasons for referral; 3. Age; 4. Sex: 5. Oral contraceptive pill (OCP) constipation; 6. Positive familial history; 7. Type of pain (acute or chronic); 8. Number of childbirths; 9. Diagnostic methods; 10. Symptoms in examination; 11. Coexistence of other diseases. Patients admitted to an emergency or elective were examined and a detailed history was taken. Diagnostic procedures have been implemented and questionnaires filled out for each patient. Regarding the fact that a group of patients were undergone emergency surgery, information about the examination of these patients and their clinical manifestations during admission was obtained by referring to the hospital records. However, the patient was again asked after surgery and the above information was also evaluated. Data were then analyzed by EpiData Software.

\section{Results and Discussion}

The distribution of the patient's age is summarized in Table 1 . Out of the 70 patients, 4 were in the age group

Table 1. The distribution of patients based on age, sex, female parity, kind of admission, chief complain, onset of pain and usage of oral contraceptive pills.

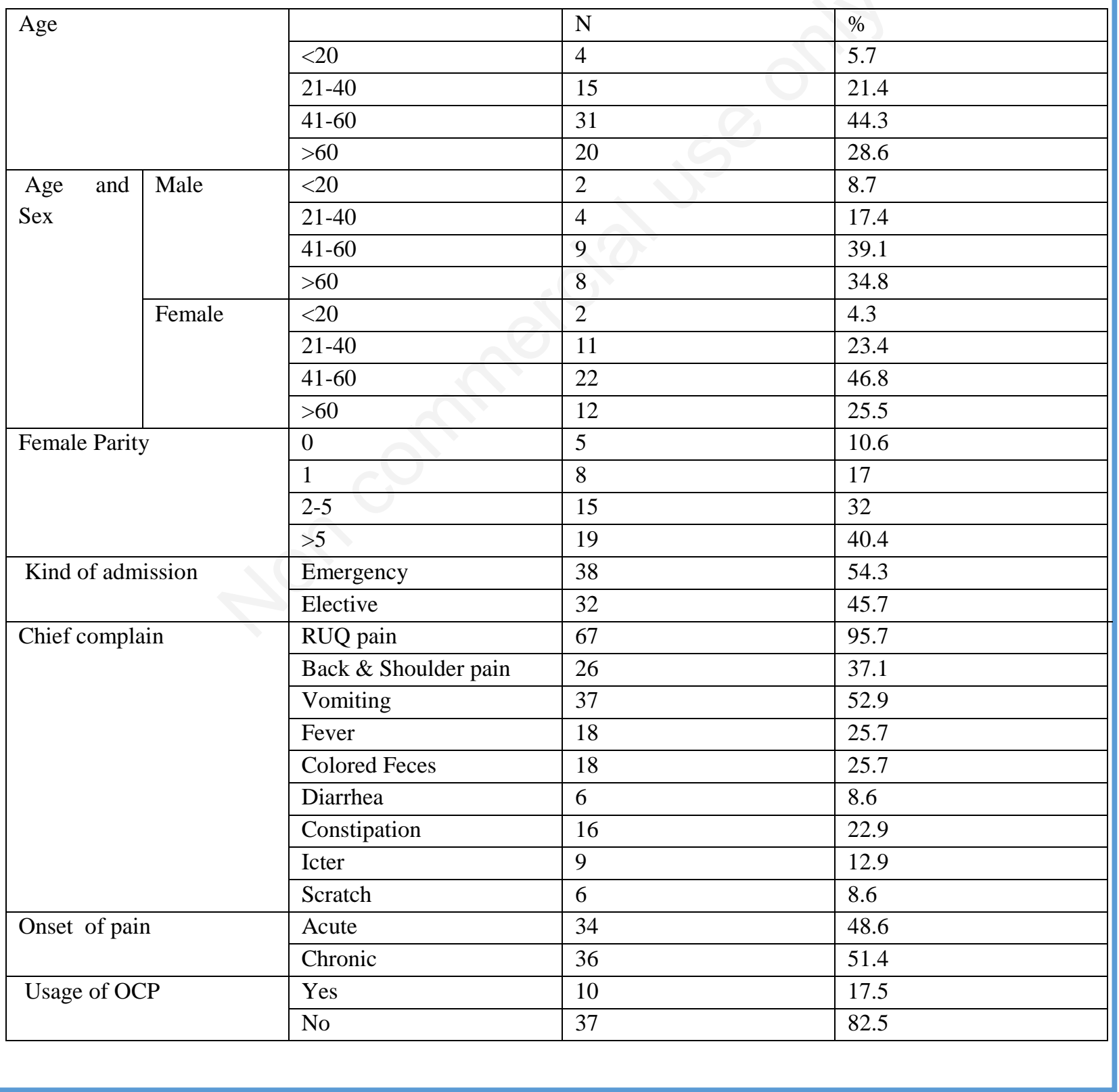




\section{Gallstone disease}

Eur J Transl Myol 28 (2): 198-202, 2018

under 20 years old, followed by patients in the age group 21-40 (15 subjects), patients in the age group of 41-60 (31), and individuals in the age group of over 60 years (20). The majority of patients were in the age group of 41 to 60 years old, accounting for $44.3 \%$ of the total. The frequency distribution of patients by age showed that the lowest frequency was in the under-20 age group (5.7\%), whit the relative frequency elevated with increasing age in the age group 21 to 40 years $(21.4 \%)$ and 41 to 60 years $(44.3 \%)$. Subsequently, in the age group above 60 years, we experienced a reduction in the frequency of patients (28.6\%). Of the 70 patients examined, 23 were male and 47 were female. Moreover,7.7\% of the men were under age 20 years of age, followed by age group 21-40 $(17.4 \%)$, age group $41-60(39.1 \%)$, and over age 60 (34.8\%). Among women, $4.3 \%$ of them were in the age

Table 2. Distribution of patients based on the diagnostic and positive procedures, character of pain, diseases and family history of gallstones.

\begin{tabular}{|c|c|c|c|}
\hline \multirow{6}{*}{$\begin{array}{l}\text { Number of years } \\
\text { Amount of usage of } \\
\text { OCP }\end{array}$} & & $\mathrm{N}$ & $\%$ \\
\hline & 1 & 5 & 50 \\
\hline & 2 & 2 & 20 \\
\hline & 4 & 1 & 10 \\
\hline & 8 & 1 & 10 \\
\hline & 9 & 1 & 10 \\
\hline \multirow{8}{*}{$\begin{array}{l}\text { Diagnostic } \\
\text { procedure }\end{array}$} & sonography & 69 & 98.6 \\
\hline & Ab.Xray & 3 & 4.3 \\
\hline & OCG & 2 & 2.9 \\
\hline & Other Procedure & 2 & 2.9 \\
\hline & OCG+Sono & 1 & 1.4 \\
\hline & Ab.Xray+ Sono & 1 & 1.4 \\
\hline & Ab.Xray+ Sono+OCG & 1 & 1.4 \\
\hline & $\begin{array}{l}\text { Ab.Xray+ Sono+ Other } \\
\text { Procedure }\end{array}$ & 1 & 1.4 \\
\hline \multirow[t]{3}{*}{ Positive procedure } & Sono & 66 & 97.1 \\
\hline & Sono+OCG & 1 & 1.5 \\
\hline & others & 1 & 1.5 \\
\hline \multirow[t]{3}{*}{ Character of pain } & Morphy sign & 4 & 51.7 \\
\hline & RUQ pain & 43 & 61.4 \\
\hline & Morphy sign+ RUQ pain & 23 & 32.9 \\
\hline \multirow[t]{5}{*}{ Associated disease } & Diabet Mellitus(DM) & 4 & 44.4 \\
\hline & Hyperlipedimia(HLP) & 3 & 33.3 \\
\hline & Hemolitic Anemia & 1 & 11.1 \\
\hline & $\begin{array}{l}\text { Hyperlipedimia(HLP)+ } \\
\text { Diabet Mellitus(DM) }\end{array}$ & 1 & 11.1 \\
\hline & Others & 0 & 0 \\
\hline \multirow{2}{*}{$\begin{array}{l}\text { Familial history of } \\
\text { Gallstones }\end{array}$} & positive & 6 & 8.6 \\
\hline & negative & 64 & 91.4 \\
\hline
\end{tabular}


group less than 20 years old, followed by age group 21 $40(23.4 \%)$, age group $41-60(46.8 \%)$ and age group Older than 60 years $(25.5 \%)$. In all age groups, except for those under the age of 20 years, the relative frequency of women was higher than that of men, but in the age group under 20, the relative frequency of men was higher than that of women $(8.7 \%$ vs. $4.3 \%)$. The highest frequency in both sexes was observed in the age group of 41 to 60 years old. Moreover, $39.1 \%$ of men belonged to the age group of 41 to 60 years old and $46.8 \%$ of women were classified in to the age group of 41 to 60 years old. Out of 47 female patients, 5 patients were divided into nulliparous group, followed by 8 primigravida and multiparous (34 patients). Among the patients with multiparous terms, 15 individuals were counted as two and five births, while 19 women had more than five births. Women who had more than five births were the most frequent, accounting for $40.4 \%$ of all women. As shown in Table 2, out of 70 patients, 38 were hospitalized as emergency cases and 32 were admitted as elective patients, representing $54.3 \%$ and $45.7 \%$, respectively. Regarding the cause of the referral, the most common complaint of pain was right upper quadrant (RUQ) $(95.7 \%)$, followed by vomiting $(52.9 \%)$, shoulder or back pain $(37.1 \%)$, fever $(25.7 \%)$, pale stools $(25.7 \%)$, constipation $(22.9 \%)$, and icterus $(12.9 \%)$. The least common cause was associated with the diarrhea $(8.6 \%)$ and itching $(8.6 \%)$, each of which consists of $8.6 \%$ of cases. Of all patients, 34 had biliary colic and 36 cases had chronic pain, which constituted $48.6 \%$ and $51.4 \%$ of the total patients, respectively. Furthermore, out of 47 female patients, 10 had oral contraceptive pill, accounting for $17.5 \%$ of women. Among women with OCP constipation, five patients had a one-year history of OCP use, following a 2-year history (2 individuals; $50 \%$ ), a 4-year history (1 individuals; $20 \%$ ), an 8 -year history (1 individuals; $10 \%$ ) and a 9-year history (1 individuals; $10 \%$ ). Table 2 shows that the most commonly used diagnostic method was sonography (98.6\% of patients), followed by simple abdominal images ( $4.3 \%$ of patients), oral cholecystography (OCG) (2.9\% of patients) and endoscopic retrograde cholangiopancreatography (ERCP); $2.9 \%$ of patients), ultrasonography with simple abdominal photographs $(1.4 \%)$, ultrasonography with OCG and simple abdominal image (1.4\%), ultrasonography plus simple abdominal image and ERCP $(1.4 \%)$. Furthermore, ultrasound positive results (Gallstones) were reported in $97.1 \%$ of patients, while $1.5 \%$ of patients had ultrasound and positive OCG, whereas $1.5 \%$ of patients showed positive results using other diagnostic methods. In addition, $61.4 \%$ of the patients showed right upper quadrant tenderness, and $32.9 \%$ of them with the RUQ tenderness were positive for the Murphy's sign . It is worth noting that only 5.7\% of the patients had a positive Murphy sign (Table 2). A total of 9 patients showed clinical entity (Gallstones) coexisting with other diseases, of which 4 cases had diabetes $(44 \%)$ followed by hyperlipidemia (3 cases;
11.12), hemolytic anemia (1 case; 11.1), and both diabetes and hyperlipidemia (1 person). Of the 70 patients, only six patients had a positive family history of gallstones, which made up $8.6 \%$ of total. Diabetes was the most common illness with gallstone disease (44\%).

Gallstone is one of the common causes of abdominal pain in the emergency department, with several factors contributing to its occurrence. Fortunately, today many risk factors are known for this condition, so that awareness of risk factors can be taken as far as possible in limiting or eliminating the underlying factors. In the present study, the highest frequency was observed in the age group of 41 to 60 years, and the lowest frequency was found in the age group of less than 20 years. Previous studies also pointed out that age increased the incidence of gallstones. ${ }^{16,17}$ This is in agreement with our study until the age of 60 , but the frequency of patients with gallstone decreases from the age of 60 . This is under the influence of various interventional factors. Perhaps different factors such as the difference in average age of life, cultural differences and different habits may be effective. It has been reported that gallstone disease was noticeable in the elderly in Iran. ${ }^{10}$ Frequency of female patients is higher than male, so that the ratio of female to male in this studyias about 2 to 1 . This is also consistent with the results of many studies world-wide. ${ }^{18-20}$ The highest frequency of patients was found in both males and females in the age group of 41 to 60 years old. The frequency of female patients enhanced with increasing the number of childbirth, where the highest frequency was seen in women who had more than 5 times childbirth, which is consistent with the information given in some studies. ${ }^{16,18}$ Regarding the way of admission, the frequency of patients who were admitted to emergency care was the higher. As to the patient's complaints and causes of referral, the most common pain was RUQ, that accounted for $95.7 \%$ of cases. In agreement with literature, in the present study vomiting was observed in $52.9 \%$ of patients. ${ }^{18}$ Pain in shoulder was the next most frequent, while the least frequent symptoms were itching and diarrhea. Patients who experienced chronic pain were more frequent than those with acute pain. Among women, $17.5 \%$ had OCP constipation. It is worth noting that $50 \%$ of women with OCP constipation had history of one-year use, followed by a 2-year history (20\%), a 4year history $(10 \%)$, a 8 -year history $(10 \%)$ and a 9 -year history (10\%). The most common symptom was RUQ tenderness, which is consistent with Lawrence (1999). ${ }^{18}$ The most common diagnostic method used in the current study was associated with ultrasonography, which was performed in $98.6 \%$ of patients. Ultrasonography was the best diagnostic tool for the above-mentioned patients, where was helpful in $97.1 \%$ of cases, and is consistent with Lawrence (1999). ${ }^{18}$

\section{List of acronyms}

OCG - oral cholecystography

OCP - oral contraceptive pill 
RUQ - right upper quadrant

ERCP - endoscopic retrograde cholangiopancreatography

\section{Author's contributions}

Authors contributed equally to the manuscript.

\section{Acknowledgments}

Thanks to dr. Magid Rezayinasab for guidance in this research. Funding: None.

\section{Conflict of Interest}

The authors declare no conflicts of interests.

\section{Ethical Publication Statement}

We confirm that we have read the Journal's position on issues involved in ethical publication and affirm that this report is consistent with those guidelines.

\section{Corresponding Author}

Leila Kanafi Vahed Department of Orthopedics, Shohada Hospital, Lahijan, Gilan University of Medical Sciences, Gilan, Iran. Phone: 00989111434497

Email: drkanafivahed@yahoo.com

\section{E-mail of co-author}

Leila Khedmat: leilakhedmat@yahoo.com

\section{References}

1. Russo MW, Wei JT, Thiny MT. Digestive and liver diseases statistics, 2004. Gastroenterolog 2004:126; 1448-53.

2. Shabanzadeh DM, Sørensen LT, Jørgensen T. Abdominal Symptoms and Incident Gallstones in a Population Unaware of Gallstone Status. Can J Gastroenterol Hepatol 2016;2016: 9730687.

3. Njeze GE. Gallstones. Niger J Surg 2013;19:49-55.

4. Acalovschi M. Cholesterol gallstones: From epidemiology to prevention. Postgrad Med J 2001;77:221-9.

5. Halldestam I, Enell EL, Kullman E, Borch K. Development of symptoms and complications in individuals with asymptomatic gallstones. Br J Surg 2004;91:734-8.

6. Rahman GA. Cholelithiasis and cholecystitis: Changing prevalence in an African community. J Natl Med Assoc 2005;97:1534-8.
7. Williams E, Beckingham I, El Sayed G, et al. Updated guideline on the management of common bile duct stones (CBDS). Gut 2017;66:765-82.

8. Dray X, Joly F, Reijasse D, et al. Incidence, risk factors, and complications of cholelithiasis in patients with home parenteral nutrition. J Am Coll Surg 2007;204:13-21.

9. Shaffer EA. Gallstone disease: Epidemiology of gallbladder stone disease. Best Pract Res Clin Gastroenterol 2006;20:981-96.

10. Massarrat S. Prevalence of gallstone disease in Iran. J Gastroenterol Hepatol 2001;16:564-7.

11. Burkitt H. George, the biliary system. In: Burkitt H. George, ed, Essential of surgery. Second ed. Longman, Singapore publishers. 1996, pp. 202-20.

12. Jorgensen T. Abdominal symptoms and gallstone disease: an epidemiological investigation. Hepatology 1989;9:856-60.

13. Noble F, Johnson C. Gallstones. Medicine 2015:689-93.

14. Vetrhus M, Berhane T, Søreide O, et al. Pain persists in many patients five years after removal of the gallbladder: observations from two randomized controlled trials of symptomatic, noncomplicated gallstone disease and acute cholecystitis. J Gastrointest Surg 2005;9:826-31.

15. Weinert CR, Arnett D, Jacobs D, et al. Relationship between persistence of abdominal symptoms and successful outcome after cholecystectomy. Arch Intern Med 2000;160:989-95.

16. Raraty MG, Pope IM, Finch M, et al. Choledocholithiasis and gallstone pancreatitis. Baillieres Clin Gastroenterol 1997:11: 663-80.

17. Uhler MI, Marks JW, Judd HL. Estrogen replacement therapy and gallbladder disease in postmenopausal women. Menopause 2000:7:162-7.

18. Lawrence W. Current surgical diagnosis and treatment. Appleton \& Lange, Norwalk. 1994:570600 .

19. Nahrwold David L. The biliary system. In: Sabiston Dawid C, ed, Sabiston textbook of surgery. 15th ed. W.B. Saunders Company. 1997:1117-51.

20. Seymour Sch. Gallbladder and extrahepatic biliary system. In: Schwartz Principles of Surgery. 7th ed. Mc Graw-Hill, 1999:1437-66.

Submission: $11 / 03 / 18$

Acceptance: $23 / 03 / 18$ 